Artigo Original

Original Article

Adriana Marques de Oliveira ${ }^{1}$ (C) Jair Licio Ferreira Santos ${ }^{2}$ (B)

Fernando Cuetos Vega ${ }^{3}$ (C) Simone Aparecida Capellini' ${ }^{1}$

Descritores

Ensino Fundamental e Médio

Leitura

Compreensão

Avaliação

Adolescente

Keywords

Education, Elementary and High School

Reading

Comprehension

Evaluation

Adolescent

Endereço para correspondência: Adriana Marques de Oliveira Departamento de Fonoaudiologia, Faculdade de Filosofia e Ciências, Universidade Estadual Paulista "Júlio de Mesquita Filho" - UNESP Av. Hygino Muzzi Filho, 737, Mirante, Marília (SP), Brasil, CEP: 17525-900 E-mail: adriana.oliveira@unesp.br

Recebido em: Setembro 05, 2018

\section{Tradução e adaptação cultural da Bateria de Avaliação dos Processos de Leitura - PROLEC-SE-R}

\author{
Translation and cultural adaptation \\ of the Reading Processes \\ Assessment Battery - PROLEC-SE-R
}

\title{
RESUMO
}

Objetivo: traduzir e adaptar culturalmente, para o Brasil, a bateria "Evaluación de los procesos lectores - PROLEC-SE-R", destinada aos escolares do Ensino Fundamental II e do Médio. Método: foram seguidos os seguintes estágios da Tradução e adaptação cultural: (1) Tradução; (2) Síntese das traduções; (3) Retrotradução; (4) Revisão por comitê de especialistas; (5) Estudo-Piloto, em que foram avaliados 70 escolares, sendo 10 para cada ano escolar, em duas sessões; e (6) Avaliação e apreciação de todos os relatórios escritos pelo pesquisador e comitê de especialistas. Resultados: o estudo-piloto não indicou necessidade de modificação nas provas do PROLEC-SE-R, tanto na versão coletiva quanto na versão individual. Os escolares apresentaram boa aceitação ao procedimento e não houve queixas ou relatos de dificuldade quanto à compreensão das provas e instruções. Conclusão: o procedimento está adaptado para a realidade brasileira, no entanto, ainda é necessário estudo de validação da população.

\begin{abstract}
Purpose: to translate and culturally adapt, for Brazil, the battery of tests "Evaluación de los procesos lectores - PROLEC-SE-R", for students of Elementary School cycle II, and Senior High School. Methods: The following stages of translation and cultural adaptation were followed: (1) Translation; (2) Synthesis of translations; (3) Back-translation; (4) Evaluation by specialist committee; (5) Pilot study: Undertaken in a sample of 70 students, 10 from each school year, in two sessions; and (6) Evaluation and appreciation of all the reports written by the researcher and specialist committee. Results: modifications to the tests of PROLEC-SE-R are not necessary as indicated in the pilot study, both in the collective and individual version. The procedure received good acceptance by the evaluated students and there were no complaints or reports of difficulty in understanding the tests and instructions. Conclusion: the procedure is appropriate for the Brazilian reality and can be used to evaluate Elementary School II and Senior High School students. A standardization study is necessary in a representative sample of the population.
\end{abstract}

Trabalho realizado no Programa de Pós-graduação em Educação, Faculdade de Filosofia e Ciências, Universidade Estadual Paulista "Júlio de Mesquita Filho" - UNESP - Marília (SP), Brasil.

${ }^{1}$ Faculdade de Filosofia e Ciências, Universidade Estadual Paulista “Júlio de Mesquita Filho" - UNESP - Marília (SP), Brasil.

${ }^{2}$ Faculdade de Medicina de Ribeirão Preto, Universidade de São Paulo - USP - Ribeirão Preto (SP), Brasil.

${ }^{3}$ Universidade de Oviedo - Oviedo (Asturias), Espanha.

Fonte de financiamento: Conselho Nacional de Desenvolvimento Científico e Tecnológico (CNPq), processo no. 140363/2013-0.

Conflito de interesses: nada a declarar. 


\section{INTRODUÇÃO}

Segundo o relatório do Programa Internacional de Avaliação de Estudantes (PISA) ${ }^{(1-3)}$, coordenado pela OCDE, o Brasil, em 2015 , ficou na $63^{\circ}$ posição no ranking geral e em $50^{\circ}$ no de leitura. Cerca de metade $(50,9 \%)$ dos escolares encontra-se abaixo do nível 2, considerado o mínimo necessário para o exercício da cidadania. Isso significa que, a cada dez alunos, cinco não atingiram as habilidades necessárias para a leitura e a compreensão.

$\mathrm{O}$ quadro retratado pelo PISA ${ }^{(1-3)}$ reflete a realidade da fonoaudiologia, na qual cresce o número de escolares maiores de 11 anos encaminhados para avaliação fonoaudiológica com queixas de dificuldades no aprendizado da leitura e da escrita. Isso torna evidente não só a fragilidade da fonoaudiologia educacional brasileira, mas também das demais profissões que atuam com a aprendizagem e a escassez de procedimentos para avaliar o desempenho em leitura e em escrita dos escolares do Ensino Fundamental II e Médio.

A fim de suprir essa lacuna, este estudo tem por objetivo traduzir e adaptar culturalmente para o Brasil o teste de "Evaluación de los procesos lectores - PROLEC-SE- $R$ "(4), destinado aos escolares do $6^{\circ}$ ao $9^{\circ}$ ano do Ensino Fundamental ciclo II e da $1^{\mathrm{a}}$ a $3^{\mathrm{a}}$ série do Ensino Médio, com provas que avaliam desde o processo léxico (reconhecimento das palavras) até o processo semântico (compreensão da leitura).

\section{MÉTODO}

Estudo de tradução e adaptação cultural aprovado pelo Comitê de Ética em Pesquisa, sob parecer $\mathrm{n}^{\circ} 1.125 .746$. Este estudo é parte da tese de doutorado "Tradução e Adaptação Cultural da avaliação dos processos de leitura (PROLEC-SE-R) para escolares do Ensino Fundamental ciclo II e do Ensino Médio" do Programa de Pós-Graduação em Educação da Faculdade de Filosofia e Ciências da Universidade Estadual Paulista "Júlio de Mesquita Filho" - FFC/Unesp/ Marília - SP, Brasil.

Os pais e/ou responsáveis assinaram o termo de consentimento livre e esclarecido e os escolares, cujos pais e/ou responsáveis assinaram o termo de consentimento, assinaram o termo de assentimento para participar da pesquisa.

A participação dos especialistas (juízes) na pesquisa também exigiu a sua concordância e assinatura do Termo de Consentimento Livre e Esclarecido.

A permissão formal para a adaptação cultural do PROLEC-SE-R foi concedida pela Tea Ediciones. O PROLEC-SE-R ${ }^{(4)}$ tem por objetivo avaliar os diferentes processos que intervêm na leitura dos escolares com idade entre 12 e 18 anos, buscando identificar as dificuldades para eles se tornarem bons leitores.

A bateria completa apresenta duas versões: 1) aplicação individual e 2) aplicação coletiva. Ambas objetivam avaliar a capacidade de leitura geral e dos processos cognitivos envolvidos quanto aos processos léxico, sintático e semântico, a fim de diagnosticar as dificuldades apresentadas na leitura e o nível de habilidade nesse processo (baixo, médio ou alto) em comparação com outros alunos do mesmo ano escolar.

A versão coletiva realiza uma avaliação breve, com a finalidade de ser utilizada em centros educativos, uma vez que permite a obtenção de informações sobre a possível presença de dificuldades nos processos de leitura de um amplo número de escolares (em sala de aula) e em menos de uma hora de aula. Cabe ressaltar que apenas a aplicação é realizada de forma coletiva. As respostas dos escolares são realizadas individualmente, em folha própria.

A bateria completa permite obter informações detalhadas de cada um dos processos avaliados. Desse modo, obter-se-á um conjunto mais amplo de dados e de informações para caracterizar as dificuldades, refinar o diagnóstico e estabelecer com maiores detalhes os objetivos da intervenção. Isso requer a aplicação de todos os testes das duas versões. Convém esclarecer que a versão coletiva pode ser aplicada de forma individual ou coletiva (segundo a conveniência da pessoa responsável pela avaliação), porém a individual somente com um escolar por vez.

\section{Tradução e adaptação cultural}

Para realizar a adaptação cultural do procedimento, foram adotados os critérios propostos por Beaton e Guillemin ${ }^{(5)}$ : Estágio 1 - Tradução; Estágio 2 - Síntese; Estágio 3 - Retrotradução; Estágio 4 - Revisão por Comitê de Especialistas; Estágio 5 - Pré-Testagem; e Estágio 6 - Avaliação e apreciação dos relatórios escritos. A descrição de cada estágio teve por referência Beaton e Guillemin ${ }^{(5)}$,Guillemin et al. ${ }^{(6)}$, Keller et al..$^{(7)}$.

\section{Processo de adaptação cultural}

Para facilitar a compreensão do processo de adaptação, optou-se por descrever suas etapas individualmente, prova a prova, na versão coletiva e na individual. Inicialmente, apresentam-se os critérios adotados para a seleção de palavras, elaboração das frases e dos textos na versão adaptada para a realidade brasileira.

\section{Critérios para seleção das palavras}

Para a seleção das palavras de alta e de baixa frequência, foram respeitados os seguintes critérios, previstos no procedimento original: 1) extensão silábica (monossílabos, dissílabos, trissílabos e polissílabos) e 2) complexidade da palavra segundo a estrutura da sílaba inicial.

Os critérios supracitados garantem que as palavras selecionadas variem em regularidade, extensão e complexidade silábica.

Para a adaptação brasileira das palavras utilizadas no PROLEC-SE-R, foi elaborado um banco de palavras, retiradas do material didático utilizado pela rede estadual de ensino de Marília (SP), do $6^{\circ}$ ano do Ensino Fundamental ciclo II até a $3^{\mathrm{a}}$ série do Ensino Médio ${ }^{(8-10)}$.

Informa-se que cada prova apresenta seu próprio critério para a seleção das palavras, apresentado na descrição de cada uma delas.

\section{Critérios para a elaboração das frases}

Os critérios apresentados pelo autor do PROLEC-SE-R espanhol ${ }^{(4)}$ para a formação das frases são os seguintes: 1) alteração de ordem canônica na colocação dos sintagmas; 2) presença de dois verbos na oração; 3 ) necessidade de manter 
disponível o primeiro sintagma enquanto se analisam os demais; e 4) existência de um nome que exerce dois papéis temáticos diferentes na oração.

Portanto, as estruturas eleitas são: 1. Período simples: a) voz ativa com objeto direto preposicionado; $b$ ) voz passiva; c) voz ativa com expressão de realce; e d) voz passiva com expressão de realce, e 2. Período composto: a) Oração subordinada adjetiva restritiva, com pronome relativo exercendo a função de sujeito e b) Oração subordinada adjetiva restritiva, com pronome relativo exercendo a função de objeto.

\section{Critérios para a elaboração dos textos}

Os textos foram traduzidos do espanhol para o português e, após definir a versão de consenso entre os tradutores, foram revisados para adequação à realidade brasileira quanto ao uso de expressões e de palavras, porém sem alterar o sentido do texto original em Espanhol.

\section{Provas versão coletiva}

Prova 1: Seleção Léxica. Para a seleção das palavras, o critério adotado foi a escolha daquelas que iniciassem com a mesma estrutura silábica e gráfica da palavra em espanhol. Por exemplo, para a palavra "silvestre" em espanhol (estrutura da sílaba inicial CVC) foi selecionada a palavra "salsicha" em português (estrutura da sílaba inicial CVC).

As pseudopalavras foram derivadas de palavras reais de baixa frequência, pertencentes ao banco de palavras do Ensino Fundamental ciclo II: E-LEITURA II $^{(8-9)}$ e do Ensino Médio: E-LEITURA III ${ }^{(8,10)}$. As palavras reais foram eleitas de acordo com a estrutura da sílaba inicial das pseudopalavras em espanhol. Portanto, se a pseudopalavra em espanhol começasse com a sílaba $\mathrm{CV}$, a palavra real eleita em português e a pseudopalavra também começavam com CV.

Para a derivação da palavra real de baixa frequência em pseudopalavra, adotou-se o critério de manter o radical da palavra real e modificar o sufixo, ou seja, fez-se a derivação por sufixação.

Na seleção léxica (SL), prova de reconhecimento entre palavras reais e inventadas, apresenta-se uma lista de 50 palavras ( 25 reais e 25 inventadas). A tarefa do escolar consiste em indicar a natureza de cada palavra. O próprio escolar deverá marcar na folha de respostas a alternativa que considerar correta. O tempo para realização da prova é de quatro minutos.

Prova 2: Categorização Semântica. Na prova de categorização semântica “Animal (A) ou não (N)?”, as palavras que correspondem a seres do reino animal foram retiradas do banco de palavras de alta, média e baixa frequência do E-LEITURA $\mathrm{II}^{(8-9)} \mathrm{e}$ do $\mathrm{III}^{(8-10)}$. Como faltaram apenas três substantivos que correspondessem a nomes de animais, foram utilizadas as palavras orca, girafa e hiena, que constam do procedimento original em espanhol.

As palavras que não correspondem a seres do reino animal provêm do banco de palavras de baixa frequência do E-LEITURA II e III, respeitando a estrutura da sílaba inicial da palavra em espanhol. Por exemplo, para a palavra em espanhol "catamarán", (estrutura da sílaba inicial: CV), em português foi eleita a palavra "catarata".
Nessa prova, apresenta-se ao escolar uma lista com 90 palavras, incluindo nomes de animais. A tarefa consiste em indicar se cada palavra corresponde a um nome de animal ou não. Para tanto, o examinando deverá anotar suas respostas na folha de respostas: opção A, se considerar que é nome de animal, ou opção N se considerar que é outro tipo de palavra. Nessa prova, é importante chamar a atenção do examinando para o tempo limite de execução que é de dois minutos.

Prova 3: Estruturas Gramaticais I (EG I). Foram utilizados os mesmos desenhos do procedimento original. Para elaboração das frases, adotaram-se os critérios citados anteriormente, adequando as frases ao desenho apresentado.

Nessa prova, são apresentados 24 desenhos, cada um com três frases (A, B e C), mais o exemplo. A tarefa do examinando consiste em verificar qual oração descreve corretamente o que o desenho representa. Para tanto, deverá marcar na folha de respostas, a opção (A, B ou C) que considerar correta. O tempo de realização da prova é de cinco minutos.

Prova 4: Juizos gramaticais. Nessa prova, são apresentadas 35 frases, sendo 18 gramaticalmente corretas e 17 incorretas. A tarefa do escolar é verificar, rapidamente, se cada oração é gramaticalmente correta ou não, marcando suas respostas na folha de respostas do seguinte modo: opção $\mathrm{C}$, se a frase for correta, ou opção I, se incorreta. Nessa prova, é importante chamar a atenção do examinando para o tempo limite de execução (dois minutos) e acalmá-lo, caso seja necessário, esclarecendo que não é preciso responder a todos os itens, mas o máximo que conseguir corretamente.

Prova 5: Compreensão Expositiva (CE). O texto é do tipo expositivo e possui dez perguntas de múltipla escolha, com quatro opções de respostas (A, B, C ou D). Apenas uma das alternativas é correta e essa deve ser anotada na folha de respostas. Nessa prova, o examinando terá de ler o texto "O Ornitorrinco" e, após a leitura, responder às perguntas sem consulta.

Deve-se conceder cinco minutos para a leitura do texto e outros cinco minutos, aproximadamente, para responder às perguntas. É importante que o aluno não consulte o texto nesse momento.

Prova 6: Compreensão Narrativa (CN). O texto apresenta dez perguntas de múltipla escolha, com quatro opções de respostas (A, B, C ou D). Deve ser anotada na folha de respostas apenas a alternativa correta. Trata-se de um texto do tipo expositivo, trabalhado com questões literais e inferenciais. As respostas podem ser dadas com consulta ao texto. Não há tempo estipulado para leitura do texto e para responder às perguntas.

\section{Provas versão individual}

Prova 7: Leitura de Palavras (LP). As palavras foram divididas por frequência e extensão, ou seja, alta e baixa frequência, curtas e longas. As palavras curtas são dissílabas e as longas, trissílabas e polissílabas.

Para a escolha das palavras, seguiram-se os critérios e as características da versão original do PROLEC-SE- $\mathrm{R}^{(4)}$, sendo respeitada a frequência das palavras e sua extensão. Na elaboração da lista de palavras do procedimento adaptado para a realidade brasileira, se a palavra em espanhol, como carta, coincidisse com a palavra em português e essa palavra estivesse no banco de 
palavras, coincidindo também com a frequência de ocorrência, a palavra era inserida na lista.

Procurou-se, ainda, garantir que a estrutura da sílaba inicial da palavra em espanhol coincidisse com a estrutura da sílaba inicial em português. Por exemplo, para a palavra carta, em espanhol, utilizou-se a palavra carta em português; para a palavra fama, em espanhol, utilizou-se a palavra fome em português. Isso, porém, não foi possível realizar com todas as palavras, visto que, obrigatoriamente, as palavras selecionadas deviam fazer parte do banco de palavras E-LEITURA II e III. O fato, no entanto, não é preocupante, pois, no procedimento original, os autores se ativeram mais à extensão da palavra e ao comprimento delas em número de letras do que à estrutura da sílaba inicial.

Apesar do exposto, procurou-se obter um equilíbrio entre as palavras, não só quanto à extensão, mas também quanto à estrutura da sílaba inicial. As palavras de alta frequência, devido ao reduzido número de palavras disponíveis para seleção, foram as que mais se distanciaram de apresentar as mesmas estruturas da sílaba inicial e de número de letras em cada estrutura. Já com a lista de palavras de baixa frequência, foi possível garantir as estruturas silábicas iniciais e o número de letras por estruturas próximas.

As listas de palavras foram divididas da seguinte forma:

* Lista 1 (LP1): 24 palavras curtas e de alta frequência com as seguintes estruturas silábicas (sílaba inicial): V (1), VV (1), VC (4), CV (8), CCV (1), CVC (8) e CVVC (1). As palavras são dissílabas constituídas por três a sete letras.

* Lista 2 (LP2): 24 palavras longas e de alta frequência com as seguintes estruturas silábicas (sílaba inicial): V (3), VC (2), CV (11), CVC (3), CCV (4) e CVV (1). As palavras são trissílabas (13) e polissílabas (11) e sua extensão varia de seis a 14 letras.

* Lista 3 (LP3): 24 palavras curtas e de baixa frequência com as seguintes estruturas silábicas (sílaba inicial): $\mathrm{V}(1)$, VC (3), CV (5), CCV (5), CVC (6), CVV (1), CCVC (2) e CVVC (1). As palavras são dissílabas com extensão entre três e seis letras.

* Lista 4 (LP4): 24 palavras longas e de baixa frequência com as seguintes estruturas silábicas (sílaba inicial): V (2), VC (2), CV (5), CVV (2), CVC (7), CCV (4), CCVC (1) e CVVC (1). As palavras são trissílabas (8) e polissílabas (16) com seis a 14 letras.

A tarefa do aluno consiste em ler, em voz alta, quatro listas de palavras (LP1 a LP4). Nessa prova, o examinador deve registrar o tempo (em segundos) que o escolar leva para ler cada lista.

Prova 8: Leitura de Pseudopalavras (LPS). As pseudopalavras foram derivadas de palavras reais de alta e de baixa frequência pertencentes à prova 1 Leitura de Palavras, conforme realizado no procedimento original em Espanhol ${ }^{(4)}$. Para a realização da derivação das palavras reais em pseudopalavras, adotaram-se os seguintes critérios: (1) manutenção do radical da palavra real e modificação do sufixo; (2) inversão de sílabas; (3) inserção de letras; e (4) alteração de uma ou mais letras.
As pseudopalavras foram divididas em curtas (pseudopalavras dissílabas) e longas (pseudopalavras trissílabas e polissílabas), divididas da seguinte forma:

* Lista 1 (LPS1): 24 pseudopalavras curtas (monossílabas e dissílabas), derivadas da lista de palavras de alta frequência, e 12 derivadas da lista de baixa frequência, com as seguintes estruturas silábicas (sílaba inicial): V (1), VC (2), CV (6), CVC (8), CCV (3), CVV (1), CVVC (1) e CCVC (2).

* Lista 2 (LPS2): 24 pseudopalavras longas, derivadas da lista de palavras de alta frequência, e 12 longas, derivadas da lista de baixa frequência, com as seguintes estruturas silábicas (sílaba inicial): V (1), VC (2), CV (7), CVC (7), CVV (1), CCV (5) e CCVC (1). As pseudopalavras são trissílabas (13) e polissílabas (11).

Da mesma forma realizada na leitura de palavras, a tarefa do aluno consiste em ler, em voz alta, as duas listas (LPS1 e LPS2). Nessa prova, o examinador deve registrar o tempo (em segundos) que o escolar leva para ler cada lista.

Prova 9: Estruturas Gramaticais II (EG II).Essa prova apresenta por objetivo avaliar a capacidade de processar diferentes tipos de estruturas gramaticais e verificar a dificuldade que se pode produzir ao utilizar distintas estruturas sintáticas. Para cada estrutura gramatical eleita, quatro frases foram adaptadas (conforme critérios de elaboração das frases, apresentados anteriormente), totalizando 24 frases.

Nessa prova, a tarefa do escolar consiste em identificar o desenho que corresponde ao indicado pela frase. Essa prova contém 24 estímulos e um exemplo. Para indicar a resposta de cada estímulo, o examinando deverá apontar para o desenho ou verbalizar o número que corresponde à sua resposta.

$\mathrm{Na}$ folha de respostas, o examinador deverá anotar a opção eleita pelo escolar, independentemente de ser correta ou não.

Prova 10: Sinais de Pontuação (SP): Texto Maldito Apêndice. Essa prova apresenta, por objetivo, avaliar a precisão de leitura e se o escolar é capaz de realizar as pausas e entonações que indicam os sinais de pontuação.

O texto é do tipo narrativo e oferece diversos sinais de pontuação diferentes. A tarefa do aluno consiste em ler em voz alta o texto intitulado "Maldito Apêndice". Enquanto isso, o examinador deverá prestar atenção à correta entonação dos sinais de pontuação marcados, anotando, nos espaços delimitados ao lado de cada sinal, um ' $\mathrm{x}$ ' unicamente em caso de erro da entonação.

Nessa prova, deve-se registrar o tempo que o aluno investe na leitura em segundos.

Prova 11: Compreensão de Leitura I: Annapurna. A tarefa do escolar consiste em ler o texto em voz alta até o final, enquanto o examinador registra o tempo que leva para leitura e anota-o na folha de respostas. A seguir, o examinador faz, uma a uma, as dez perguntas e avalia as respostas como acerto (A) ou erro (E). Algumas características importantes dessa prova são:

A) O examinador faz, uma a uma, as perguntas para o escolar e pode repeti-las quantas vezes considerar necessário.

B) O escolar pode consultar o texto para responder às perguntas. 
O texto é do tipo expositivo com perguntas literais e inferenciais. Apresenta por objetivo avaliar a capacidade de o escolar responder às perguntas do tipo inferenciais, que só podem ser respondidas com a compreensão total do texto, integrar as informações na memória e realizar as inferências correspondentes.

Prova 12: Compreensão de leitura II: Os Papuas Australianos. A tarefa do escolar consiste em ler o texto pausadamente, em silêncio e de forma compreensiva, durante cinco minutos. A seguir, o examinador faz, uma a uma, as 10 perguntas, apoiando-se no caderno de estímulos, e avalia as respostas como acerto (A) ou erro (E). As características importantes dessa prova são:

A) O examinador não deve registrar o tempo da leitura, porém deverá controlar que a leitura silenciosa não ultrapasse cinco minutos.

B) O examinador faz as perguntas, uma a uma, ao escolar, enquanto o aluno as lê mentalmente na sua parte do caderno de estímulos. Nesse caso, não se deve repetir a leitura das perguntas.

C) $\mathrm{O}$ aluno não pode consultar o texto para responder às perguntas.

O texto é expositivo e as perguntas do tipo literal, com o objetivo de avaliar a capacidade de o escolar extrair a informação do texto e recordá-la.

Prova 13: Compreensão Oral: Texto Os Esquimós. Nessa prova, o examinador lê um texto para o aluno duas vezes, em voz alta e pausadamente, pronunciando com clareza. A seguir, realiza, uma a uma, as 10 perguntas, apoiando-se no caderno de estímulos, e analisa as respostas como acerto (A) ou erro (E), com o objetivo de avaliar a compreensão oral de texto do examinando. As características importantes dessa prova são: (1) o examinador deve ler o texto, em voz alta, duas vezes; (2) o aluno não pode consultar o texto enquanto o examinador o lê; (3) o examinador realiza as perguntas uma a uma enquanto o escolar acompanha mentalmente o enunciado na sua parte do caderno de estímulos. Não se deve repetir a leitura das perguntas e (4) o aluno não pode consultar o texto para responder às perguntas.

\section{Tradução do procedimento para a língua portuguesa}

Como já referido, a tradução e a adaptação cultural ocorreram simultânea e interdependentemente. Recorda-se, portanto, que a apresentação em tópicos distintos é apenas didática. Nos parágrafos subsequentes, descreve-se como a tradução foi conduzida.

\section{Tradução (estágio 1)}

O instrumento original foi traduzido para a língua-alvo, o português brasileiro. Beaton e Guillemin ${ }^{(5)}$ recomendam que sejam realizadas duas traduções (T1 e T2) e que cada tradutor detalhe, por escrito, as etapas da tradução, as dúvidas e as dificuldades. Um tradutor deve conhecer os objetivos do procedimento e estar familiarizado com a linguagem acadêmica, enquanto o segundo não deve ter conhecimento do objetivo do procedimento ou conhecer o tema. Esse segundo profissional é chamado, por Beaton e Guillemin ${ }^{(5)}$, de "tradutor ingênuo", pois, por não ser influenciado pelo meio acadêmico, oferecerá uma tradução capaz de refletir a linguagem utilizada pela população-alvo, muitas vezes destacando significados ambíguos do procedimento original.

Essa etapa, portanto, foi realizada por dois tradutores, nativos do Brasil, com domínio das duas línguas, Espanhol e Português. Um é formado em letras com especialização em espanhol e o outro em Fonoaudiologia, atuante na área de leitura e escrita, com certificado DELE B2, outorgados pelo Instituto Cervantes. Somente a esse último tradutor foi explicado o objetivo do procedimento.

Aos tradutores foi solicitado que a versão do instrumento para a língua portuguesa fosse realizada de forma independente, preservando a equivalência semântica de todos os itens do procedimento original.

\section{Síntese das traduções (estágio 2)}

Esse estágio refere-se à síntese das traduções em uma versão única. Para a obtenção da versão de consenso, os dois tradutores se reuniram com as pesquisadoras que explicaram o objetivo dessa etapa.

Os tradutores foram orientados que deveriam entrar em consenso sobre as divergências entre as traduções, criando assim uma única versão. $\mathrm{O}$ encontro foi realizado na Faculdade de Filosofia e Ciências - FFC/UNESP - Marília (SP), Brasil.

As pesquisadoras participaram da reunião e acompanharam o processo para a elaboração dessa versão, auxiliando os tradutores nas eventuais dúvidas. Ao final desse encontro, obteve-se a primeira versão da tradução do procedimento.

\section{Retrotradução (estágio 3)}

Finalizadas as adaptações culturais necessárias, dois tradutores realizaram a retrotradução (português - espanhol). Os tradutores não foram os mesmos da primeira etapa. Um tradutor tinha o espanhol como língua materna e lecionava esse idioma em uma escola de idiomas do interior de São Paulo. O segundo era professor de espanhol, porém de outra escola de idiomas da mesma cidade. Ambos os tradutores não tinham conhecimento dos objetivos do procedimento e trabalharam na tradução da versão única para o espanhol sem ter acesso ao original. Foram criadas duas retrotraduções (BT1 e BT2).

A finalidade dessa etapa foi verificar se a versão refletia o conteúdo da versão original. Em seguida, a versão original e as duas retrotraduções foram comparadas e corrigidas para que os erros de tradução e de interpretações fossem excluídos. Neste estudo, como foi necessário realizar a adaptação de todos os estímulos para a realidade brasileira, optou-se por focar as descrições e instruções do procedimento.

\section{Revisão por comitê de especialistas (estágio 4)}

Nesse estágio, deve-se chegar a um consenso, a partir de todas as versões das traduções produzidas, de modo que seja elaborada uma versão pré-final. 
Os materiais disponibilizados ao comitê foram o procedimento original e as traduções juntamente com os relatórios correspondentes para clarificar as decisões tomadas nas fases anteriores.

Esse estágio tem por objetivo realizar as mudanças necessárias no instrumento para garantir tanto a equivalência cultural quanto a semântica, idiomática e conceitual.

O trabalho de equivalência semântica, cultural, idiomática e conceitual foi realizado com a ajuda de uma profissional experiente, formada em Letras, para adequação à realidade brasileira quanto ao uso de expressões e de palavras, verificando a correção ortográfica e gramatical. Quando necessário, as frases foram reestruturadas para respeitar a gramática do Português, porém sem alterar o sentido do texto original em Espanhol.

Nesse estágio, a pesquisadora e a orientadora do estudo se reuniram com o comitê de especialistas para analisar o procedimento original e todas as versões produzidas para, assim, elaborar uma Versão Pré-Final. Foi esclarecido que a pesquisadora, antes de entregar a versão única para o comitê, realizou modificações com a profissional de Letras para adequação das frases e textos, bem como correção gramatical e ortográfica.

O comitê de especialistas foi formado pelos pesquisadores do Laboratório de Investigação dos Desvios da Aprendizagem - LIDA sendo três doutores em educação e quatro doutorandos, bem como dois docentes da Faculdade de Filosofia e Ciências - FFC/UNESP/Marília(SP), Brasil.

\section{Aplicação da versão pré-final do instrumento - estudo- piloto (estágio 5)}

Estudo-piloto com a finalidade de detectar possíveis erros, avaliando a qualidade da adaptação e os aspectos práticos de sua aplicação. Esse estágio permite refinar a redação das instruções e das provas, assim como verificar o tempo de aplicação do instrumento.

Participantes

Os escolares participantes do estudo-piloto foram selecionados aleatoriamente. Foram avaliados 70 alunos do $6^{\circ}$ ano do Ensino Fundamental ao $3^{\circ}$ ano do Ensino Médio, de escolas públicas estaduais, individualmente, sendo 10 para cada ano escolar.

Adotaram-se os seguintes critérios de inclusão: 1) estar regularmente matriculado no Ensino Fundamental ciclo II ou Médio; 2) assinatura do Termo de Consentimento Livre e Esclarecido pelos pais ou responsáveis; 3) assinatura do Termo de Assentimento. Foram excluídos: 1) escolares que se recusaram a participar, embora os pais ou responsáveis tivessem assinado o termo de consentimento; 2) escolares com diagnóstico interdisciplinar de transtorno de aprendizagem, dislexia e transtorno de déficit de atenção e hiperatividade; 3) queixa de aprendizagem; 4) alteração de linguagem ou fala; 5) prejuízo na acuidade visual e auditiva; 6) diagnóstico de síndromes genéticas ou neurológicas; 7) histórico de repetência; 8) rebaixamento intelectual.

Essas informações foram observadas no prontuário escolar ou obtidas a partir dos professores.

Dos 70 escolares que participaram do estudo-piloto, 40 (57,1\%) são do Ensino Fundamental II (média etária: 12,4 anos, desvio padrão: 1,19) e $30(42,9 \%)$ do Ensino Médio com 15,8 anos em média, desvio padrão 1,1 .

Procedimentos:

- Provas de avaliação dos Processos de Leitura - versão coletiva, aplicada no primeiro encontro.

- Provas de avaliação dos Processos de Leitura - versão individual, aplicada no segundo encontro.

A versão coletiva foi aplicada em uma sala de aula disponibilizada pela escola, com número máximo de dez alunos e mínimo de cinco. Os alunos não pertenciam necessariamente à mesma sala de aula.

A versão individual foi aplicada em sala de aula disponibilizada pela escola ou na sala de leitura, no mesmo período de aula do escolar. Para a retirada do aluno da aula, era solicitada, previamente, autorização ao professor. A saída do aluno estava condicionada à autorização do docente responsável e ao conteúdo que estava sendo ministrado no momento.

\section{Avaliação e apreciação de todos os relatórios fornecidos pelo pesquisador e comitê de especialistas (estágio 6)}

Todas as traduções e retrotraduções bem como o material utilizado para o estudo-piloto e o material com as correções realizadas após essa etapa foram enviados para processo de auditoria com o objetivo de verificar se todas as etapas do processo de tradução e adaptação cultural haviam sido seguidas. Após este estágio, não foi permitido alterar o conteúdo do procedimento.

Dois pesquisadores da Fonoaudiologia Educacional foram convidados a participar do processo de auditoria, juntamente com os fonoaudiólogos do Laboratório de Investigação dos Desvios da Aprendizagem - LIDA. Eles tiveram acesso ao projeto de pesquisa aprovado pelo CEP e foram orientados sobre os propósitos da pesquisa. Foi-lhes solicitado que indicassem se cada etapa do processo de tradução e de adaptação cultural tinha sido seguida e se o procedimento, mediante as informações entregues e estudo-piloto, estava adequado para avaliação dos processos de leitura em escolares do Ensino Fundamental II e Médio.

\section{RESULTADOS}

Os resultados são apresentados de acordo com os estágios da tradução. Esclarece-se que o processo de adaptação do procedimento, de seleção de palavras, de adequação das frases e dos textos foram descritos no tópico relativo ao processo de adaptação.

\section{Estágio 1 (tradução) e estágio 2 (síntese das traduções)}

Dois tradutores fizeram as traduções separadamente, sem se comunicarem. As decisões referentes aos termos utilizados e à melhor estrutura para a versão em português foram detalhadas em relatório para a pesquisadora deste estudo. No Estágio 2, os tradutores se reuniram com as pesquisadoras e fizeram uma versão única das duas traduções.

Os tradutores apresentaram dificuldades na tradução das palavras isoladas, pois algumas delas, dependendo do 
contexto, tinham significados diferentes (exemplo: selo - verbo, selo - substantivo). Duas expressões idiomáticas do texto "Maldito Apêndice" não foram traduzidas ("Pues a mí, plin" e "¿Cree usted que me chupo el bisturi?”), pois as expressões não possuem equivalentes no português.

Tanto o tradutor 1 como o 2 traduziram "Papuas" como "papues" seguindo a forma de escrita do espanhol e, na frase “En qué se basan para decir que la demografía de los papúes es de signo decreciente?", optaram por traduzir signo por sinal, mas alegaram que poderia ser signo, signo linguístico. No texto "Os esquimós", o Tradutor 1 traduziu "hundido" por "soterrado" e o tradutor 2 por "afundado". Na frase "en la que se sienta el esquimal prácticamente hundido entre pieles", optou-se por soterrado na versão de consenso.

Os tradutores divergiram quanto ao uso de série e ano para a tradução da seriação escolar. Juntamente com as pesquisadoras, optou-se por usar ano escolar. Ambos os tradutores explicaram que, nos textos do procedimento em espanhol, foi muito utilizado o pronome "Les" (pronome de complemento indireto usado no espanhol para subentender o sujeito). Para a versão de consenso, optou-se por sempre repetir o nome do sujeito.

As instruções e perguntas em espanhol foram feitas em ordem indireta. Os tradutores optaram, na versão de consenso, por utilizar a ordem direta para facilitar a compreensão do público-alvo. Quanto às palavras, não houve preocupação com as traduções que poderiam ter mais de um significado, pois não poderiam ser aproveitadas (considerando que as palavras frequentes e não frequentes da Espanha não são as mesmas do Brasil); portanto, as palavras foram retiradas do banco de palavras elaborado para este estudo.

Após finalizar a versão única, o trabalho foi enviado para uma profissional formada em letras. As pesquisadoras, junto com a profissional, realizaram as adequações das instruções, frases e textos para facilitar sua compreensão.

As expressões "Pues a mí, plin" " "¿Cree usted que me chupo el bisturi?" foram definidas com essa profissional considerando o contexto do texto: "Para mim deu" (Pues a mí, plin) e "O senhor quer ensinar o Padre Nosso ao vigário?” (¿Cree usted que me chupo el bisturi?). A palavra "papues" foi substituída por "papuas" e a palavra "soterrado", utilizada para traduzir "hundido", foi substituída por "escondido".

Finalizada essa etapa, realizou-se o processo de adaptação do procedimento (descrito acima) antes de seguir para o estágio 3 - retrotradução.

\section{Estágio 3 (retrotradução)}

Nessa etapa, verificou-se que as instruções e textos refletiam o conteúdo da versão original. Quanto às frases, apesar de elas manterem o significado do procedimento original, a estrutura gramatical precisou ser adequada ao Português. Quanto aos textos, apenas as expressões idiomáticas e gírias não correspondiam à versão do procedimento em Espanhol e, em algumas frases, a estrutura gramatical precisou ser alterada; porém não foi modificado o sentido do texto. Detalhes acerca das alterações quanto à estrutura gramatical foram explicadas acima, no processo de adaptação das provas.

\section{Estágio 4 (revisão por comitê de especialistas)}

Os juízes concordaram que as instruções e textos refletem o conteúdo da versão original; porém as frases e textos, apesar de manterem o significado do procedimento original, tiveram as estruturas gramaticais alteradas para a realidade brasileira. Os especialistas apenas indicaram alterações nas pseudopalavras, pois não estavam adequadas.

Na versão individual, o comitê apontou que as pseudopalavras "lagridade", "sociedal", "dantavem", "trafiteiro", "finalizagem" e "vizinheiro" precisavam ser alteradas por problemas na derivação, pois facilmente poderiam ser ativadas palavras de vizinhança ortográfica (regularizações dessas pseudopalavras em palavras reais). As pseudopalavras "promable" e "cuicirto" foram indicadas para substituição, pois a complexidade poderia prejudicar a leitura. Na versão coletiva, foi indicada a substituição da pseudopalavra "historiadilio" pelo mesmo motivo.

Outra observação realizada foi quanto ao item 24 da prova 3 "Estruturas Gramaticais", pois os desenhos número três e quatro eram iguais. Como os desenhos utilizados foram os mesmos do procedimento original, as pesquisadoras entraram em contato com a TEA Ediciones. Eles enviaram o desenho correto, uma vez que já haviam feito essa modificação no procedimento original.

A aprovação da versão final do instrumento ficou condicionada à correção dos desenhos supracitados, pois essa modificação era necessária para que o estudo-piloto pudesse ser realizado. Contudo, não foi necessário reunir novamente o comitê para nova aprovação.

\section{Estágio 5 (aplicação da versão pré-final do instrumento - estudo-piloto)}

Entre os escolares do Ensino Fundamental II, a média de tempo nas provas da versão coletiva foi de 42,7 minutos $(\mathrm{DP}=4,0)$ e para o Ensino Médio 42,0 minutos $(\mathrm{DP}=4,6)$.

$\mathrm{Na}$ versão individual, foi de 35,5 minutos $(\mathrm{DP}=6,2)$ para o Ensino Fundamental II e 31,7 minutos $(\mathrm{DP}=4,7)$ para o Ensino Médio.

O estudo-piloto não indicou necessidade de modificação nas provas do PROLEC-SE-R, tanto na versão coletiva quanto na versão individual. Houve apenas modificação no caderno de respostas, na versão do avaliador, em que uma pergunta se encontrava diferente do procedimento. No texto "Esquimós", na pergunta três, havia erro de digitação na frase: "Por que os esquimós precisam da iluminação, mais do que outros povos?", no lugar de outros povos, estava escrito outro povo.

Os escolares apresentaram boa aceitação ao procedimento e não houve queixas ou relatos de dificuldade quanto à compreensão das provas e instruções.

\section{Estágio 6 (avaliação e apreciação de todos os relatórios fornecidos pelo pesquisador e comitê de especialistas)}

Com a finalização das traduções, das retrotraduções, do estudo-piloto e adequação indicada no estudo-piloto, chegou-se à versão final do procedimento (versão coletiva, versão individual e folha de respostas). Dois pesquisadores da Fonoaudiologia 
Educacional participaram do processo de auditoria, juntamente com os fonoaudiólogos (doutores e mestres) do LIDA, para verificar se as etapas do processo de tradução e adaptação haviam sido seguidas e cumpridos todos os critérios.

O processo de auditoria concluiu que todas as etapas foram cumpridas e que o procedimento estava apto a prosseguir para a fase de caracterização da população.

\section{DISCUSSÃO}

Para realizar a adaptação cultural do procedimento, foram adotados os critérios propostos por Beaton e Guillemin ${ }^{(5)}$. A técnica de tradução e adaptação, objetivando equivalência cultural, como o caso das palavras classificadas em frequência de ocorrência e estrutura sintática das orações, não é alcançável apenas por técnicas de tradução e adaptação, levando em consideração os critérios linguísticos da língua portuguesa do Brasil ${ }^{(11-14)}$.

Portanto, o processo adotado não é o de apenas traduzir o procedimento para o Português. O processo se assemelha ao desenvolvimento de um novo instrumento, nesse caso, buscando a sua equivalência cultural para que possa ser utilizado no Brasil sem a perda de sua eficácia ${ }^{(11-14)}$.

O estudo-piloto foi realizado com a finalidade de detectar possíveis erros e avaliar a qualidade da adaptação e os aspectos práticos de sua aplicação, assim como verificar o tempo de aplicação do instrumento. Quanto ao tempo de realização das provas, tanto na versão coletiva quanto na individual, a média dos escolares brasileiros é bem próxima à dos escolares espanhóis ${ }^{(4)}$ que apresentaram tempo médio de 45 minutos tanto na versão coletiva quanto na versão individual.

Após a finalização de todas as etapas, afirma-se que a tradução e adaptação para a língua portuguesa foi satisfatória, porém ainda será necessário estudo de validação relativo aos escolares do Ensino Fundamental II e Médio para sua utilização.

\section{CONCLUSÃO}

O objetivo de traduzir e adaptar culturalmente, para o Brasil, o PROLEC-SE-R, foi atendido. O procedimento está adaptado à realidade brasileira ainda que se faça necessário estudo de validação da população de escolares do Ensino Fundamental II e Médio.

\section{AGRADECIMENTOS}

À Profa. Maria Derci da Silva Nóbrega pela consultoria no processo de adaptação cultural, revisão ortográfica e gramatical. À Alina Cappelazzo e Alexandra Beatriz Portes de Cerqueira César pelo auxílio na coleta de dados do estudo-piloto. Ao Conselho Nacional de Desenvolvimento Científico e Tecnológico (CNPq).

\section{REFERÊNCIAS}

1. Brasil. Programme for internacional student assessment (PISA) results from PISA 2012 [Internet]. Brasília: Instituto Nacional de Pesquisas Educacionais Anísio Teixeira - INEP; Ministério da Educação - MEC; 2012 [citado 2016 jul. 10]. Disponível em: http://download.inep.gov.br/ acoes internacionais/pisa/resultados/2013/country note brazil pisa 2012 . pdf

2. Brasil. INEP: Instituto Nacional de Estudos e Pesquisas Educacionais Anísio Teixeira, MEC: Ministérios da Educação. Brasil no Pisa 2015: análises e reflexões sobre o desempenho dos estudantes brasileiros/OCDE: Organização para a Cooperação e Desenvolvimento Econômico. São Paulo: Fundação Santillana; 2016.

3. Organisation for Economic Co-operation and Development. PISA 2015 assessment and analytical framework: science, reading, mathematic and financial literacy [Internet]. Paris: OECD; 2016 [citado 2016 jul. 10]. Disponível em: http://www.oecd.org/pisa/

4. Cuetos F, Arríbas D, Ramos JL. PROLEC-SE-R - Batería para la evaluación de los procesos lectores en secundaria y bachillerato - revisada. Madrid: TEA Ediciones; 2016.

5. Beaton DE, Bombardier C, Guillemin F, Ferraz MB. Guidelines for the process of cross-cultural adaptation of self-report measures. Spine. 2000;25(24):3186-91. http://dx.doi.org/10.1097/00007632-20001215000014. PMid:11124735.

6. Guillemin F, Bombardier C, Beaton D. Cross-cultural adaptation of healthrelated quality of life measures: literature review and proposed guidelines. J Clin Epidemiol. 1993;46(12):1417-32. http://dx.doi. org/10.1016/0895-4356(93)90142-N. PMid:8263569.

7. Keller SD, Ware JE Jr, Gandek B, Aaronson NK, Alonso J, Apolone $\mathrm{G}$, et al. Testing the equivalence of translations of widely used response choice labels: results from the IQOLA Project - International Quality of Life Assessment. J Clin Epidemiol. 1998;51(11):933-44. http://dx.doi. org/10.1016/S0895-4356(98)00084-5. PMid:9817110.

8. Oliveira AM. Tradução e adaptação cultural da avaliação dos processos de leitura (PROLEC-SE-R) para escolares do Ensino Fundamental ciclo II e do Ensino Médio [tese]. Marília: Faculdade de Filosofia e Ciências: Universidade Estadual Paulista "Júlio de Mesquita Filho"; 2017.

9. Oliveira AM, Capellini SA. E-LEITURA II: banco de palavras para leitura de escolares do Ensino Fundamental II. CoDAS. 2016a;28(6):778-817. http://dx.doi.org/10.1590/2317-1782/20162016049. PMid:27982255.

10. Oliveira AM, Capellini SA. Banco de palavras para leitura de escolares do ensino médio: E-Leitura III. Rev CEFAC. 2016b;18(6):1404-46. http:// dx.doi.org/10.1590/1982-0216201618610516.

11. Jorge MR. Adaptação transcultural de instrumentos de pesquisa em saúde mental. In: Gorentein C, Andrade LHSG, Zuardi AW, editores. Escalas de avaliação clínica em psiquiatria e psicofarmacologia. São Paulo: Lemos Editorial; 2000. p. 53-58.

12. Mattos P, Serra-Pinheiro MA, Rohde LA, Pinto D. Apresentação de uma versão em português para uso no Brasil do instrumento MTA-SNAP-IV de avaliação de sintomas de transtorno do déficit de atenção/hiperatividade e sintomas de transtorno desafiador e de oposição. Rev Psiquiat Rio Gd Sul 2006;28(3):290-7. http://dx.doi.org/10.1590/S0101-81082006000300008.

13. Malloy-Diniz LF, Mattos P, Leite WB, Abreu N, Coutinho G, Paula JJ, et al Tradução e adaptação cultural da Barrat impulsiveness scale(BIS-11) para aplicação em adultos brasileiros. J Bras Psiquiatr. 2010;59(2):99-105. http:// dx.doi.org/10.1590/S0047-20852010000200004.

14. Ramos LMBC, Rocha M, Gomes I, Schwanke CHA. Tradução e adaptação cultural do APQ- Aging Perceptions Questionnaire para a língua portuguesa brasileira. Rev Bras Geriatr Gerontol. 2012;15(2):233-42. http://dx.doi org/10.1590/S1809-98232012000200006.

\section{Contribuição dos autores}

AMO participou da concepção, do planejamento do projeto de pesquisa, coleta dos dados, interpretação dos dados, redação e revisão crítica do manuscrito; JLFS participou do planejamento do projeto de pesquisa, da análise e interpretação dos dados e revisão crítica do manuscrito; FCV participou do planejamento do projeto de pesquisa e da revisão crítica do manuscrito; SAC participou da concepção, planejamento e orientação do projeto de pesquisa, da redação e revisão crítica do manuscrito. 